\title{
Internet of things to protect the environment: a technological transdisciplinary project to develop mathematics with ethical effects
}

\author{
F. S. Tortoriello ${ }^{1} \cdot$ I. Veronesi ${ }^{1}$ \\ Accepted: 7 March 2021 / Published online: 25 March 2021 \\ (C) The Author(s) 2021
}

\begin{abstract}
In a society that has to reconcile two areas which are conceptually very distant from each other, such as interdisciplinarity and specialization, the education for young people is essential to form a thought to understand complexity, thanks also to the stimuli deriving from increasingly powerful and interconnected technological and IT environments. So, it is essential to identify teaching-learning processes and methods that allow students to understand and act adequately with a constantly evolving reality. Transdisciplinary themes can be introduced to enrich the students' curriculum by anchoring them strongly to the wealth of emerging technologies, using their potential and designing educational activities focused on technology and attractive to the various spheres of knowledge. In this paper is presented an experimental activity of designing Smart objects in the Internet of Things conducted with students of the "Mathematical High School" project.
\end{abstract}

Keywords Transdisciplinarity $\cdot$ Internet of things $\cdot$ Education $\cdot$ Technology $\cdot$ Mathematical language

\section{Introduction}

The world of school interfaces and cooperates, daily, with the social and economic political dynamics that represent the contemporary super-technological and fluid society, in which complexity does not only bring wealth but also problems. A society that should have its purpose the wellbeing of the individuals who compose it, well-being understood not only on the economic level, but above all in the psychological context (Bauman 2000). Our complex society stimulates the complexity of thought precisely from the complexity of reality. Reasoning complex means being planetary citizens, part of a large community. In such a complex and dynamically changing society, it is essential to educate young people to a thought capable of decoding and interpreting the stimuli also thanks to the potential for efficiency and interconnection of a technological and information-technology (IT) environment (Morin 1999, 2014). So, it must always be at the forefront to identify teaching-learning processes and methods that

\section{Veronesi}

iveronesi@unisa.it

1 Department of Mathematics, University of Salerno, Fisciano, Italy allow students to understand and act adequately with a constantly evolving reality. Therefore, the school is no longer that institution of a few decades ago that could repropose paths and themes developed and well-articulated, but always repeated because they are were always valid and invariant, currently it must know how to train young people to change and choose in a world that increasingly accelerated in the direction of technological development (Chweya et al. 2019). Educational processes can benefit from new technologies both for the enrichment of the equipment, that teachers can use because, thanks to the Cloud paradigms, institutes are no longer required to continually renew their IT assets, as they can take advantage of products, memories, shared spaces also reducing management costs and because, thanks to the introduction of new technological contexts, transdisciplinary themes can be addressed in the class which enrich the students' curriculum by anchoring it strongly to the wealth of emerging technologies and their potential (Nicolescu 2002; Kuyoro et al. 2015). If on the one hand the technological offer has enriched the possibilities of innovative didactic paths also thanks to e-learning distance courses, virtual learning, open learning (Glicoric et al. 2015; Bottino 2015), that link physical and virtual spaces (Moreira et al. 2017) and thanks to the sharing of resources, it offers more democratic 
education (Johnson et al. 2015; Selinger et al. 2013; Wellings and Levine 2009). On the other hand it requires impulses of experimentation in learning and teaching by teachers (Bagheri and Haghighi Movahed 2016; Bottino et al. 2009) who must therefore be trained to use technologies not only as a means of expanding their skills and areas of discussion but also as an object of the didactic activities to be developed in technological orientation with the "millennial" students, the so-called digital natives. Designing educational activities focused on technology but attractive to the various spheres of knowledge means approaching the way young people interface with reality, it means creating a school open to innovation that meets the needs of future generations. When ethical and sustainability issues of the planet are introduced into the courses, then students understand how technology can facilitate and implement virtuous processes (Delors 1996).

The teaching activity described in this paper is tailored to respond perfectly to a transdisciplinary teaching model that has a solid theoretical framework, enriched by the potential of new technologies and it is one of the many paths proposed in the activities of the Project "Mathematical High School" of the Department of Mathematics of the University of Salerno. In this project, mathematics is the centre of an articulated didactic action and acts as a link between the different disciplinary areas with a view to an innovative and fruitful dialogue between scientific and humanistic cultures (Capone et al. 2017). In particular, this paper will deal with the issue of pollution and environmental protection thanks to Smart Ideas for a Smart World. In the second section the legislative contextualization will be sketched, in the third section the background of the Internet of Things with brief historical references will be presented. The articles published on the Internet of Things will be reported in the fourth section, in the fifth section Internet of Things will be presented as a new educational tool for students and in the sixth section the experimentation of an Internet of Things Project, conducted with students of upper secondary schools participating in the Project "Mathematical High School" will be described. In the seventh and eighth section, results and conclusions will be presented.

\section{Contextualization}

The Italian Ministry of Education in 2002 launches the ForTic, the "National teacher training plan on information and communication technologies" which involves around 180,000 teachers. It is the first ministerial action aimed at a conscious and effective use of technology. With the aim of promoting organizational and educational models, in 2006 the European Parliament defines "digital literacy"
(Recommendation of The European Parliament and of The Council 2006) as a key competence for lifelong learning and the European Commission in 2009 activates a plan for Europe about Internet of Things (Commission 2009). In 2007 the National Digital School Plan (PNSD) is presented and activated in schools. In 2015, the last PNSD intervenes incisively in the role of teachers, learning spaces and teaching.

Furthermore, the specific objectives of science learning listed in the Scientific High School Guidelines emphasize how ".... In addition, it will be possible to carry out indepth studies on (....) Themes chosen for example among those related to ecology, energy resources, renewable sources, to the conditions of equilibrium of environmental systems (biogeochemical cycles), to new materials (....). These approaches will be carried out, whenever possible, in conjunction with the courses in physics, mathematics, history and philosophy. The connection with the physics course, in particular, will favour the acquisition by the student of complementary languages and tools that will allow him to deal with more complex and interdisciplinary problems with greater familiarity".

Moreover, in mathematics, the Guidelines state: "The computer tools available today offer suitable contexts for representing and manipulating mathematical objects. Mathematics teaching offers numerous opportunities to become familiar with these tools and to understand their methodological value. The path, when this proves to be appropriate, will favour the use of these tools, also in view of their use for data processing in other scientific disciplines".

As can be seen from the PNSD, the instrument with which the Ministry of Education implements a strategic part of the reform of the good school Law 107 of 2015 the educational challenge that the school is facing is related to building a critical thought to familiarization with information technologies through the enhancement of logical and computational thinking. As recommended by the Organization for Economic Co-operation and Development (OECD), students must transform themselves from consumers, that is simple users of digital environments and tools, to critical consumers and producers, that is creators and designers of digital contents and architectures. Thanks to technology, an awareness of one's own time can be developed that exploits the digital environment to overcome the fragmentation and hyper-specialization of the complexity paradigm and create connections between different areas of knowledge, scientific, technological, humanistic and social knowledge through the computational logical critical thinking as a bridge between the two cultures (Rogora and Tortoriello 2018). Therefore, the mathematical language becomes a key and a simple and rigorous model for reading the present time. Students must 
acquire critical thinking to develop transversal problem solving skills, independent judgment, flexibility and innovation in the search for solutions. In this context, digital technologies intervene to support all dimensions of transversal skills (cognitive, operational, relational, metacognitive).

But they also fit vertically, as part of the literacy of our time and fundamental skills for a full, active and informed citizenship, as anticipated by the Recommendation of the European Parliament and the Council of Europe and as even better underlined by frameworks, such as twenty-first Century Skills, promoted by the World Economic Forum.

If on the one hand the world of technology acts as a vehicle for non-neutral and verifiable information and can be a subsidy to teaching and individual disciplines, on the other hand it is an actor and active agent of major global changes both in the social economic and in educational and ethical contexts so as to require the acquisition of skills in "digital citizenship" necessary to be able to read our time.

In the implementation lines of the PNSD there is a strong push to deepen laboratory activities in digital teaching project activities relating to secondary schools (which already saw in the documents on the reorganization of high schools and technical institutes of 2010 a clear imprint on constructivist models that clearly exceed the cognitivist ones) but also attention at all school levels since all projects, aimed at deepening logical-computational thinking, are encouraged with coding and design of digital paths both in primary school than in first grade secondary school. The document shows that at present there is no univocally recognized library to which reference is made and the need to produce applied didactic paths that can be used extensively and easily re-modulated in the classroom is underlined, a sort of portfolio that teachers can draw on.

If, therefore, on the one hand we have the Ministry of Education which strongly urges the introduction of technology in the classroom and we see the institutions working in this direction, on the other hand we observe the world of the Internet of Things which could enrich the students' curricula but which has so far not given effective impulses in teaching. In fact, there are no models and examples that stimulate and support the activities of the teachers, even those who would like to introduce activities and paths but lack the skills on technologies that implement the Internet of Things or even in schools the funds and tools to design are lacking.

In this perspective, numerous courses and activities have been activated in schools related to the conscious and effective use of technology, design and programming through digital facts. In particular, robotics can become a strategic development axis for smart specialization policies.

\section{Background}

The Internet of Things (IoT) is a neologism introduced in telecommunications to describe the extension of the Internet to the world of objects and to concrete places. The multinational joint-stock company Gartner Inc. that deals with strategic consultancy, research and analysis in the field of information technology has defined IoT as:

The network of physical objects that contains embedded technology to communicate and sense or interact with their internal states or the external environment (Gartner 2017).

A primordial idea of the IoT date back to 1982, when some researchers applied sensors to a drink machine of the Carnegie Mellon University and through the network connection managed to recognize its operational status.

Raji (1994) published a popular article in which he talked about the possibility of integrating the network with various household objects, such as household appliances, or with machines of large industries (Mattern and Folerkemeier 2010).

But the term "Internet of Things" was introduced firstly in 1999 by Kevin Ashton, the co-founder and executive director of Auto-ID Center, as the title of a presentation he made at Procter \& Gamble. With this new way of interpreting the Internet, Ashton intended to propose a new way of use: things can acquire intelligence and be able to communicate by accessing data and information from other parts without any help from human (Ashton 2014).

To measure the extent of innovation in communication by the Internet-of-things just think that since 2008, the number of physical items connected to the Internet has exceeded the number of people on Earth (Evans 2011).

The developments of RFID (radio-frequency identification) technology allowed IoT to design and develop "Smart" objects in order to facilitate the management of objects by computers benefitting from developments in the fields of electronics and wireless communication to enable digital and communication capabilities in appliances in quite every field of our everyday life... image capture and management, technical systems, sensors, cars without the driver, wearable devices, remote monitoring, company systems, medical instruments and much more than this. In fact, the use is extended to any real world object capable of interacting on the network, therefore participating in the creation of digitized, flexible and intelligent processes interacting with cloud services capable of performing sophisticated analysis processing on big data, machine learning and AI.

In the latest Worldwide Semi-annual Internet of Things Spending Guide published in June 2019, IDC (International 
Data Corporation is the first global company specialized in market research, consultancy services and event organization in the ICT and digital innovation sectors) expects total global spending on IoT projects to reach \$ 1.2 trillion in 2022 , with an average annual growth of $13.6 \%$ over the next five years. The study reveals that the biggest push to purchase IoT solutions is coming from investments in the manufacturing and transport sectors and many developments also concern security and healthcare solutions.

Looking more specifically at Italy, according to recent data from the Internet of Things Observatory of the School of Management of the Milan Polytechnic (founded in 2011 to respond to the growing interest of public and private companies in the potential offered by the new IoT paradigm) the turnover generated by IoT solutions in Italy in 2018 was 5 billion euros, a number which represents a $35 \%$ increase over the previous year.

IoT is destined to change the way we act at work and in daily life because it allows even people who live in remote contexts with limited resources to be able to participate instructor the advantages of a global network also for the management of documents and resources hardly available (Singh and Vardhan 2019). Over the last few years there has been a pressing increase in intelligent objects so as to induce international organizations to work to design communications networks necessary to make the IoT safer and prevent possible problems and this new paradigm and its development can lead to data transmission (Tewari and Gupta 2020). This led the research to investigate the protocols of the various data transmission and communication models and evaluate their effectiveness (Al-Qerem et al. 2020). Another aspect that involves the scientific world is the efficient management of an increasingly significant amount of data which therefore requires effective storage of the data to be archived thanks to their compression (Hossain et al. 2019) without neglecting the ethical aspect, i.e. the design for the reduction in energy consumption during from transmission and processing of Big data.

\section{Literature review}

Analysing the articles published on the applications of the Internet-of-things to teaching, there are many documents that propose the implementation of school and university spaces and their enrichment, thanks to the IoT with the design of workspaces and interconnected virtual environments, see Ray (2018), Samaniego and Deters (2017), Raji (1994), and Ahmad et al. (2016).

There are numerous articles that identify IoT as an efficient and effective tool to improve the physical and mental well-being of users thanks to wearable technology as Sena et al. (2016), Sapargaliyev (2014), Bayani et al. (2017) and Ashwin et al. (2015).

There are articles that exploit the potential of IoT to carry out analyses on students' study behaviour, research methodologies, habits as Tuncay Saritaf (2015), Pedersen (2013), Chweya et al. (2019), Mershad and Wakim (2018), Banica et al. (2017), Bagheri and Haghighi Movahed (2016), Adorni et al. (2012), and Bottino (2015).

As an example, the visual persistence time is monitored in the various points of the page when reading a document to also deepen the learning dynamics based on more or less prolonged pauses on a formula or image or phrase.

There are also articles as Anohah (2017), Fragou and Mavroudi (2020) with a systematic review of research publications, where the various papers of the last years are classified by topics.

There is no evidence, however, or at least the in-depth research conducted on the available documents has not brought them to light, on didactic research projects that study how to plan activities of Smart objects designed by students. In other words, there is no research in which the IoT is at the same time subject and object of implementation by the students themselves: object because the design benefits from IoT technology, subject because the students, starting from their own personal experiences and the needs of the companies that they have perceived and made their own, develop and prototype a smart object for man and the planet.

\section{Internet of things-a new educational resource for students}

The IoT is a very wide technological environment that can play a peculiar role in the teaching-learning processes by enhancing the methodological-didactic approach to the traditional contents of the curricula by implementing computer skills which are the key to reading the evolutionary processes of contemporary society. The Rabardel's theory of instrumentation in the distinction between artefact and instrument (Rabardel 2002) is fundamental for interpreting the Internet of Things role, in fact the artefact is a not necessarily physical object that can be construed at various degrees of awareness: if IoT is considered in the "whole package" as a single artefact or if it is considered as a set of artefacts each of them with its own specific action (for example each type of software or Hardware with which the IoT object has been designed and/or is used to work).

In fact, the way in which the artefact is used is not trivial. An IoT smart object can be a simple channel of interaction as unknown medium commonly used in daily life, and we know how many realities of the IoT we 
encounter in everyday life, even in an unconscious way. Otherwise, IoT becomes a powerful instrument for a psychological construction of transversal skills that transcend curricular paths. In this use, it is much more than an artefact and students acquire awareness of the efficiency and effectiveness of the use of the tool. Rabardel distinguishes the tool in relation with its use, when there is a significant relationship between the artefact and the user for a specific type of task he call it "instrument" and includes techniques and mental schemes that the user must develop and apply during the use of the artefact. IoT therefore arises to the role of instrument in the interaction process that the student establishes in cognitive activity with and through it.

The students' process of transforming an artefact into an instrument is called Instrumental Genesis and is a continuous evolution that creates a bilateral relationship between the artefact and the student that leads to implement and modify the instrument by shaping it to his own teaching and formative needs (Hoyles and Noss 2003). In teachers' teaching actions the IoT becomes for students an instrument of knowledge and competence and expertise as well as an artefact for developing the process.

From the point of view of the use of language to manage knowledge and report results, Sfard points out how "The claim about the role of discourse (communication) in disseminating innovation seems self evident" (Sfard 2015).

Translating, perhaps with a slight forcing, Sfard's thought on the use of language in mathematics (Sfard 2012), it can be said that new technologies constitute a new communicative language in the development of which two conceptions follow one another, the one in which the technological language is seen as a tool, in an operational interpretation, and the conception in which the language becomes a specific object of study of itself, in an analytical interpretation.

Compared to what emerged in the short analysis, it can be concluded that IoT, with its technology, its tools and its languages, represents an unprecedented educational challenge that allows teachers to overcome traditional disciplinary frontiers.

\section{IoT project}

\subsection{Methodologies}

The research activity has been developed with a constructionist approach, in fact the centrality of the development of an IT idea and its coding in executable software is the fundamental principle of constructionism (Harel and Papert 1991; Kafai and Resnick 1996; Kafai 2006). The new frontiers of technological and IT scenarios allow the creation of constructivist learning environments (Chachil et al. 2015), also thanks to the functionality of mobile devices which are seen as artefacts capable of solving the zone of proximal development (ZPD) of Vigotsky (1987).

Constructionism bases its foundations on constructivism, a theory of developmental sciences which asserts that knowledge is built by students through the active experience and which identifies learning with the process of building and adapting mental representations (Papert 1990, 1993,). Constructionism focuses explicitly on the methods of development and realization of cognitive artefacts that facilitate the development of specific learning as the mind learns by handling materials and building objects and devices. Artefacts can be both physical and virtual and computerized ones, and supports students' IT processes, i.e. the conceptual understanding of the information acquired through experience (Sheridan et al. 2014).

The artefact also plays the role of a representative object of the evolution of thought, such that knowledge develops further during the process.

In the field of scientific research, constructionist theory has been applied to analyse the learning of mathematical, physical and engineering concepts in the design project through the resolution of specific problems (Kolodner et al. 2003; Mbogo et al. 2013; Pereira and Rodrigues 2013). The various design phases, the structuring of an idea, the proposal for solving a problem, the creation of a prototype, the testing of the artefact the revision of the project, may highlight some misconceptions or conceptual errors that allow students to rework their knowledge adapting it in order to achieve measurable results (Fortus et al. 2005; Kolodner et al. 2003).

\subsection{Overhead analysis of the proposed approach}

In the contemporary reality that is evolving so rapidly and that sees changes in the paradigms of research and work thanks to the technological implementation that provides new perspectives for sharing materials and results, it is important that the school world provides students with keys to choose their university studies knowingly and to understand the world around them. It is an increasingly complex and articulated reality that cannot simply be described through the study of textbooks but must be experienced in the ways and times suitable for high school students through experimental investigative paths that allow to understand, at least in a qualitative way, the dynamics underlying the management of shared data, the protection of them and the potential that technology offers to future generations.

This study is a qualitative research centred on the use of technologies, in particular of the IoT to improve the quality of life of citizens with a great attention to the ecological messages of environmental protection and the 
enhancement of the skills of mathematics, physics, science and computer science for the design, construction and programming in the prototype. In fact, for the completion of the project, students had to deepen crosscutting issues, such as the management of spreadsheets for data analysis, the study of a programming language, pollution and environmental protection, the study of electrical circuits for the assembly of the prototype. For the teachers it was an opportunity to highlight how theoretical concepts addressed during the course of studies are the essential substrate for the development of concrete projects. The influence of technology can be observed in many aspects of the educational path from the involvement of the students in the didactic activities from the creation of didactic moments on non-curricular subjects starting from the students' requests (Soares and Martin 2014). Technology was a disruptive push that led to rethinking the teaching-learning processes (Ranieri and Pieri 2014).

From an educational and didactic point of view, the experience of working in a group to build a floating pollution detector allowed students to understand how important cooperation is to transform ideas into concrete projects and how powerful the Internet can be to provide information that can be used by all. It is enough to know how to look.

They also realized that to make the world better, the world needs many small smart-ideas. This sensitivity must come first of all from the school, which should teach to students to believe that every small contribution of each one can help the world to become better and more liveable for future generations.

All the activities related to this project were carried out with constant exchanges of ideas, advice and suggestions among students, with professors and with families who indirectly but actively lived the participation of their sons in the project. It was possible to find out the effectiveness of teaching activities both in the enthusiasm with which the students worked in this project and in the scientific and technical skills they acquired, which they also showed in presenting their projects in various scientific conferences.

\subsection{The project}

The project that will be presented in this article is about an activity carried out with 50 students of the Mancini Mathematical High School in Avellino (Italy) in collaboration with the research group of the Department of Mathematics of the University of Salerno (Italy). It lasted several months and involved the performance of a prototyping experiment of a sustainable idea for the environment and reproducible with contained costs. The activity has been developed from the definition of the objectives, to the theoretical planning with software already known by the participants, to the verification of cost benefits and to the sharing of the proposals.

It has been conducted as a problem-posing process, strongly hoped for educational but little implemented in curricular teaching. How are "smart objects" made? How is a prototype made? The IoT generation sets to work with digital fabrication. The topics dealt with evidently have prerequisites in the competences of the various disciplines (sciences, physics, computer science, economy, mathematics...) but have been then developed in a transdisciplinary vision.

Italian school law requires school and work alternation activities that take place during non-school hours to create a link between the world of school and the world of universities and companies, so the teachers, coordinated by the researchers of the University, have structured a transdisciplinary path for the students with laboratory methodology in a learning-by-doing approach.

The intent aim of the laboratory project of the Mathematical High Schools, that we present in this paper, is to make students aware of the potential of technology in the contemporary world through research firstly theoreticalscientific and then technological, let them explore smart ideas aimed at designing tools and objects to protect the environment and, as far as possible, to build the prototypes of the projects developed by groups of students. In the activities, students dealt with the problem of pollution and social ethics in solidarity from the various points of view with the curricular teachers of the individual disciplines that interpenetrated in the treatment of the themes, making the schematic subdivision of the contents to which the school current has accustomed us. Then extracurricular meetings followed in which students were divided into groups. After having defined the field of action of their project, they searched the net for ideas similar to those they wanted to develop and technical news related to the technology available to be able to produce them.

Many engaging and effective design ideas emerged from the activities carried out and the students presented or will present the result of their works at the final exams of the course of study. Digital desks for a fully technological classroom have been designed; waste containers have been designed with optical readers capable of recognizing particular QR-codes to be installed on individual objects in order to allow automatic differentiation; compensatory tools have been designed for students with learning difficulties due to dyslexia dysorthography or dyscalculia and in particular a pen with sensors has been designed that with particular functions helps students, an app with a platform consisting of a series of facilitation activities for students, such as the automatic reading of a written text but also a chat and the sharing of problems and/or reflections for students who have these difficulties. Automatic methods of 
reconnaissance of the chemical values in the land for cultivation were also designed for optimizing crops both outdoors and in the greenhouses.

Two groups of students then reached even more advanced levels of work by building the prototype of their project.

One group focused on a pollution problem that we are often not led to think about as pollution in our homes. It has therefore designed robotic arms to be inserted in the windows with sensors that are able to recognize the presence of polluting substances in the air by imagining the installation for example in rooms with stoves or fireplaces and in kitchens but also considering the pollution of closed places due to radon. They have planned and designed the programming through an app both for openings programmed or activated at particular times to favour the exchange of air inside the rooms in case of exceeding the threshold values, and with a standardized timing according to the reference temperatures selected by the user. The students also built a miniature house by designing the robotic arms connected to the windows with a microcontroller, also thinking about the economic aspect, that is, building tools with a modest cost (of a few tens of euros) for each robotic arm and therefore easily reproducible.

The students of the other group designed a float equipped with microcontroller and sensors to analyse waterways, transmit data to databases and make them available on the web and report the danger in progress to the competent authorities. The original idea of the project was born from the daily experience of the students and is dedicated to their own territory: the pollution of water. Water is an indispensable element for life and unfortunately the only river that flows in the neighbouring areas of the school is the river Sarno and it is in disastrous conditions of water pollution. The students, in the days immediately preceding, had faced in class some Latin texts which showed that ancient poets and writers wrote in their writings and poems that once it was navigable and full of fish but in the latest published statistics it has emerged that it is the most polluted river in Europe. Students also observed the information made available by the press that highlighted the causes of the pollution of the Sarno River. There are the numerous chemical companies that for years have illegally discharged and which continue to discharge industrial waste residues into the river. In fact, cases of death from leukemia and cancer above the national average have been recorded according to the survey of the Department of Medicine of the University of Salerno.

The students intend to report the spillage of harmful substances into waterways. They have designed a float composed by an immersed part equipped with sensors that analyse in real time the concentration of chemical substances dissolved in water and verify their quantity to be monitored. The sensors are chosen depending on local information and geographical conditions, for example if you know the industries in the vicinity or if you were aware of waste deposits that could be polluting.

Then, the data collected is sent to a microcontroller and they are transmitted to a database to check if they are in the ranges of allowed values. If the concentration values of the substances are up to standard, the luminous led lights present on the float remain with a steady light on; instead the led light flash if the values are not in the parameters. In the last case, the device sends an alert signal to the competent authorities for security alarm.

To avoid handling toxic chemicals in order to calibrate the sensors, the professor of chemistry suggested to the students to use only the Ph-sensor and the conductivity sensor, because the work had to be continued even at home without adequate security measures. However, these two sensors are sufficient to verify that substances that alter the chemical balance are dissolved in the water. The other sensors then allow determining the chemical elements present. To power all the electronic components, the actual feasibility of using the photovoltaic panels mounted on the top has been designed and verified. The possibility of anchoring the float to the seabed was also considered to prevent it from being dragged by the current.

A website and an app were designed with information on the water pollution of the main pollutants, on the virtuous behaviour that can reduce this pollution. A section was also dedicated for the dissemination of news in database format so that each citizen can have real-time information updated by the sensors installed in the waterways.

Students also paid attention to the economic aspect of the project, so that the construction was reasonable and reproducible in other areas; they therefore considered the specific cost of the individual components to be used, from sensors to photovoltaic panels, and assessed the economic impact on a large-scale production. Even more important to consider, in a cost-benefit analysis, the high expenditure of resources that must be foreseen for the reclamation of polluted places very high risk for public health instead of a modest economic investment for a device that acts as an alarm bell and that signals the pollution of rivers in real time, thus acting as a deterrent. It allows a considerable saving for the community in a wider view of the problem. The students also suggested a topological tessellation of the mapping of the Sarno River, which was the source of inspiration for their project, constituting a network of floats to monitor the entire watercourse.

After developing the planning and laboratory phases, the students have been involved in scientific dissemination activities. The projects developed by the various working groups have been presented in scientific conferences and educational events at national and international level, 
where students presented the activities carried out to a public of peers and of professors expert in the scientific field. In particular, the two projects described in greater detail in this paper have been presented at the National Conference of Mathematics and Sciences that took place in 2019 at the Department of Mathematics of the University of Salerno because they are an effective example of the transposition of mathematical contents into scientific contexts and wider ethical spheres, where math is not the subject of the activities but constitutes the necessary instrument to interpret the data and build the programs for the IoT tools, for the apps and the websites.

The National Conference of Mathematics and Sciences organized by the Department of Mathematics of the University of Salerno is an activity of scientific dissemination that is part of a large macro-project organized by the Department of Mathematics of the University of Salerno that foresees a rich series of national and international conferences in which are drawn and shared bridges, relatednesses and stimuli between mathematics and other disciplines (literature, history, philosophy, art, science...). The aim of this activity is to broaden the connections between the individual disciplines to observe the reality that surrounds us with a "universal eye" and that sees in mathematics the fulcrum of the various interpretative languages interconnections.

\section{Results}

The didactic activity carried out with the students of designing and realizing the prototypes was constantly monitored in order to report the didactic fallout that unconventional in-depth courses may determine in the students involved. The observation of learning styles, operational practices and personal relationships were summarized in reports that highlighted the high educational impact of these courses. The responses of parents and students to satisfaction and evaluation questionnaires of the activities carried out were also monitored.

Students' understanding of the problem of pollution, the design and management of tables of values related to chemical analyses carried out by the design and implementation of a Smart object in C language and the wise use of effective algorithms to map topologically the spaces involved in their project. The in-depth analysis of digital technological environments and their possible uses to protect the environment have shown that placing students with their needs and knowledge at the centre of the didactic planning, allows to deepen the contents of the curricular programs in a trans-disciplinary key. Appropriately motivated students are able to understand concretely the need of a systematic theoretical study in order to face a practical realization.

In particular, it is appropriate to reiterate the empathic and motivational aspect (Goleman 1995) that avant-garde projects have for young people: they are passionate and spend much more time studying and deepening the issues that are necessary for the realization of the project than the time they would devote to the same study of the contents in a traditional didactic activity. In addition to this, the young people confronted with high profile professional environments that knew how to stimulate them and enrich with their experiences. The need to deal with working environments for the design and construction of their prototype and with the academic world in scientific dissemination activities in didactical laboratories and conferences, enriched students' vocabulary by bringing them to work on the exhibition fluidity of their communications and the formal rigor of their written reports.

The highlighted improvement did not only concern the use of the Italian language but also implemented the knowledge in the micro-languages of the areas in which they worked.

\section{Summary and conclusions}

Experimental technological research activities, such as those illustrated in this paper, prove to be effective in terms of didactic relapse thanks to the laboratory approach that puts students at the centre of their learning processes. The collaboration between schools, universities and the world of research makes it possible to present young people with technologically advanced innovative activities and projects that help young people choose their university and working future. On the other hand, it is evident that the structuring of such complex laboratory projects requires an intense planning effort in order to make a highly productive teaching method become systematic. In the light of the positive impact encountered in students after the experimental activity, other laboratories have been planned and are being developed which focus on the use of new technologies in teaching. In fact, on the one hand such didactic activities require ex-ante rigorous and organized planning and structuring of interventions, on the other hand they produce great involvement by the actors and provide intense stimuli for the construction of critical thinking (Piro 2015) in a complex society, such as the contemporary one, giving information, notions and skills that help to analyse, recognize and know how to choose in an advanced technological world. 
Authors contribution Both authors, FST and IV, contributed to the conception and design and to the acquisition, analysis and interpretation of the data; drafted and revised the article and approved the version to be published; agreed to be accountable for all aspects of the work in ensuring that questions related to the accuracy or integrity of any part of the work are appropriately investigated and resolved.

Funding Open access funding provided by Università degli Studi di Salerno within the CRUI-CARE Agreement. The IoT project had no sources of funding, non-financial interests, informed consent of the participants.

\section{Declarations}

Conflict of interest The authors declare that they have no conflict of interest.

Ethical approval This article does not contain any studies with human participants or animals performed by any of the authors.

Open Access This article is licensed under a Creative Commons Attribution 4.0 International License, which permits use, sharing, adaptation, distribution and reproduction in any medium or format, as long as you give appropriate credit to the original author(s) and the source, provide a link to the Creative Commons licence, and indicate if changes were made. The images or other third party material in this article are included in the article's Creative Commons licence, unless indicated otherwise in a credit line to the material. If material is not included in the article's Creative Commons licence and your intended use is not permitted by statutory regulation or exceeds the permitted use, you will need to obtain permission directly from the copyright holder. To view a copy of this licence, visit http://creativecommons. org/licenses/by/4.0/.

\section{References}

Adorni G, Coccoli M, Torre I (2012) Semantic web and internet of things supporting enhanced learning. J e-Learn Knowl Soc $8(2): 23-32$

Ahmad G, Usman M, Soomro TR (2016) Internet of things (IoT): an overview. J Inf Commun Technol 10(1):121-130

Al-Qerem A, Alauthman M, Almomani A, Gupta BB (2020) IoT transaction processing through cooperative concurrency control on fog-cloud computing enviroment. Soft Comput 24:5695-5711

Anohah E (2017) Paradigm and architecture of computing augmented learning management system for computer science education. Int J Online Pedag Course Des 7:2

Ashton K (2014) That "internet of things" thing. RFID Journal LLC. http://www.rfidjournal.com/articles/view?4986

Ashwin K, Perumal AA, Krishnakumar S, Maheshwari M (2015) RFID Based student attendance and monitoring system. Int J Innov Res Comput Commun Eng 3(1):305-310

Bagheri M, Haghighi Movahed S (2016) The effect of the internet of things (IoT) on education business model. In: 12th International conference on signal-image technology and internet-based systems (SITIS) - IEEE computer society. pp 435-441

Banica L, Burtescu E, Enescu F (2017) The impact of internet-ofthings in higher education. Sci Bull Econ Sci (University of Pitesti) 16(1):53-59

Bauman Z (2000) Liquid modernity. Polity Press, Cambridge

Bayani M, Leiton K, Loaiza M (2017) Internet of things (IoT) advantages on e-learning in the smart cities. Int $\mathrm{J}$ Dev Res 7(12):17747-17753
Bottino RM (2015) La Didattica nell'era digitale. A cura di V. Campione. Bologna: Il Mulino. pp 287-294

Bottino RM, Artigue M, Noss R (2009) Building European collaboration in technology-enhanced learning in mathematics. In: di N, Ludvigsen BS, De Jong T, Lazonder A, Barnes S (eds) Technology-enhanced learning-principles and products. Springer, pp 73-87

Capone R, Rogora E, Tortoriello FS (2017) La matematica come collante culturale nell'insegnamento. Matematica, Cultura e Società. Rivista dell'Unione Matematica Italiana 2(3):293-304

Chachil K, Rias RM, Engkamat A, Sarkawi A (2015) Interactive multimedia-based mobile application for learning iban language. Jurnal Teknologi 75(3):41-46

Chweya R, Ibrahim O, Nilashi M (2019) IoT in higher learning institutions: opportunities and challenges. J Soft Comput Decis Supp Syst 6(6):1-8

Commission, European. Internet of Things-An action plane for Europe. COM(2009) 278. 2009. http://eur-lex.europa.eu/LexUr iServ/site/en/com/2009/com2009_0278en01.pdf

Delors J (1996) Learning: the treasure within; report to UNESCO of International Commission on Education for the Twenty-first Century (highlights)

Evan D (2011) The internet of things. Cisco Blog. 11. http://>bit.ly/ mVzJa6

Fortus D, Krajcik J, Dershimer RC, Mamlok-Naaman RW, Marks R (2005) Designed-based science and real-world problem-solving. Int J Sci Educ 27(7):855-879

Fragou O, Mavroudi A (2020) Exploring internet of things, mobile computing and ubiquitous computing in computer science education: a systematic mapping study. Int J Technol Educ Sci $4(1): 72-85$

Gartner (2017) Gartner insights on how to lead in a connected world. http://www.gartner.com/imagesrv/books/iot/iotEbook_digital. pdf

Glicoric N, Uzelac A, Krco S, Koradevic I, Nikodijevic A (2015) Smart classroom system for detecting level of interest a lecture creates in a classroom. J Ambient Intell Smart Environ 7(2):271-284

Goleman D (1995) Emotional intelligence: why it can matter more than IQ. Bloomsbury

Harel IE, Papert SE (1991) Constructionism. Ablex Publishing, Norwood

Hossain K, Rahman M, Roy S (2019) IoT data compression and optimization techniques in cloud storage: current prospects and future directions. Int J Cloud Appl Comput 9(2):43-59

Hoyles C, Noss R (2003) What can digital technologies take from and bring to research in mathematics education? In: Bishop dAJ, Clements MA, Keitel C, Kilpatrick J, Leung FKS (eds) Second international handbook of mathematics education, vol 1. Dordrecht, pp 323-349

Johnson L, Backer S, Estrada V, Freeman A (2015) The NMC horizon report: 2015 higher, education. The New Media Consortium, Austin

Kafai YB (2006) Constructionism. In: Sayer dK (ed) Cambridge handbook of the learning sciences. Cambridge University Press, Cambridge

Kafai YB, Resnick M (1996) Constructionism in practise: designing, thinking, and learning in a digital world. Routledge, London

Kolodner JL, Camp PJ, Crismond D, Fasse B, Gray J, Holbrook J (2003) Problem-based learning meets case-based reasoning in the middle-school science classroom: putting learning design into practise. J Learn Sci 12(3):495-547

Kuyoro S, Osisanwo F, Akinsowon O (2015) Internet of things (IoT): an overview. In: 3rd International conference on advances in engineering sciences and applied mathematics. London, pp 53-58 
Mattern F, Folerkemeier C (2010) From the internet of computers to the internet of things. In: di K, Sachs I, Guerrero PP (eds) From active data management to event-based systems and more, vol 6492. Springer, Berlin, pp 242-259

Mbogo C, Blake E, Suleman H (2013) A mobile scaffoholding application to support novice learners of computer propgramming. In: Proceedings of the sixth international conference on information and communications technologies and development, pp 84-87

Mershad K, Wakim P (2018) A learning management system enhanced with internet of things applications. J Educ Learn $7(3): 23-40$

Moreira F, Ferreira MJ, Cardoso A (2017) Higher education disruption through iot and big data: a conceptual approach. In: di P, Zaphiris A (eds) Learning and collaboration technologies. Novel learning ecosystems. LCT 2017. Lecture notes in computer science, vol 10295. Springer, Iannou

Morin E (1999) Seven complex lessons in education for the future

Morin E (2014) Enseigner à vivre: Manifeste pour changer l'éducation. Actes Sud I Play Bac

Nicolescu B (2002) Manifesto of transdisciplinarity. State University of New York Press, pp 147-152

Papert S (1990) Mindstorms; children, computers and powerful ideas. Basic Books Inc, New York

Papert S (1993) The children's machine: rethinking school in the age of the computer. Basic Books, New York

Pedersen I (2013) Ready to wear (or not): examinig the rhetorical impact of proposed wearable devices. In: 2013 IEEE international symposium on technology and society (ISTAS): social implications of wearable computing and augmediated reality in everyday life. Toronto, pp 201-202

Pereira OR, Rodrigues JJ (2013) Survey and analysis of current mobile learning applications and technologies. ACM Comput Surv 46(2):1-35

Piro F (2015) Manuale di educazione al pensiero critico - comprendere e argomentare. Editoriale scientifica Napoli

PNSD. Piano Nazionale Scuola Digitale. www.istruzione.it/scuola_ digitale/

Rabardel P (2002) People and technology — a cognitive approach to contemporary instruments

Raji R (1994) Smart networks for control. IEEE Spectr 31(6):49-55

Ranieri M, Pieri M (2014) Mobile learning. Dimensioni teoriche, modelli didattici, scenari applicativi. Unicopli, Milano

Ray PP (2018) A survey on internet of things architectures. J King Saud Univ Comput Inf Sci 30(3):291-319

Recommendation of The European Parliament and of The Council of the 18 December 2006 on key competences for lifelong learning (2006/962/EC). https://eur-lex.europa.eu/legal-content/EN/ TEXT (2006)
Rogora E, Tortoriello FS (2018) Matematica e cultura umanistica. Archimede 2:82-88

Samaniego M, Deters R (2017) Internet of smart things-iost: using blockchain and CLIPS to make things autonomous. In: 2017 IEEE international conference on cgnitive computing, pp 9-16

Sapargaliyev D (2014) Wearable technology in education: from handheld to hands-free learning. In: First international conference ICTE 2014. Hong Kong, pp 55-60

Selinger M, Sepulveda A, Buchan J (2013) Education and the internet of everything. Cisco Consulting Services and Cisco EAMAR Education Team

Sena P, D'Amore M, Brandimonte MA, Squitieri R, Fiorentino A (2016) Experimental framework for simulators to study driver cognitive distraction: brake reaction time in different levels of arousal. Transp Res Procedia 14:4410-4419

Sfard A (2012) Development of mathematical discourse: some insights from communicational research

Sfard A (2015) Learning, commognition and mathematics. In: The Sage handbook of learning. D. Scott \& Hargreaves, London

Sheridan K, Halverson ER, Litts B, Brahms L, Jacob-Priebe L, Owens $\mathrm{T}$ (2014) Learning in the making: a comparative case study of three makerspaces. Harv Educ Rev 84(4):505-531

Singh N, Vardhan M (2019) Distributed ledger technology based property transaction system with support for IoT devices. Int J Cloud Appl Comput 9(2):60-78

Soares A, Martin NL (2014) Teaching non-beginner programmers with app inventor: survey results and implications. In: Proceedings of the information systems educators conference ISSN

SRI, Consulting Business Intelligence (2008) Disruptive Civil Technologies, Appendix F: the internet of things, background. http://www.dni.gov/nic/PDF_GIF_confreports//_F.pdf

SRI, Consulting Business Intelligence (2008) Disruptive Civil Technologies - six technologies with potential impacts on US interests out to 2025. http://www.fas.org//nic/.pdf

Tewari A, Gupta AA (2020) Security, privacy and trust of different layers in internet-of-things (IoT) framework. Future Gener Comput Syst 108:909-920

Tuncay Saritaf M (2015) The emergent technological and theoretical paradigms in education: the interrelations of cloud computing (CC), connectivism and internet of things (IoT). Acta Polytech Hung 12(6):161-179

Vigotsky L (1987) Mind in society: the development of higher psycological processes. Harvard University Press, Harvard

Wellings J, Levine MH (2009) The digital promise: trasforming learning with innovative uses of technology. Sesame Workshop

Publisher's Note Springer Nature remains neutral with regard to jurisdictional claims in published maps and institutional affiliations. 